\title{
Bone marrow mononuclear stem cells: potential in the treatment of myocardial infarction
}

This article was published in the following Dove Press journal:

Stem Cells and Cloning:Advances and Applications

3 December 2009

Number of times this article has been viewed

\author{
Anne-Laure Leblond \\ John O'Sullivan \\ Noel Caplice \\ 'Centre for Research in Vascular \\ Biology (CRVB), Biosciences Institute, \\ University College Cork, Cork, \\ Ireland
}

Correspondence: Anne-Laure Leblond Biosciences Institute, University College Cork, College Road, Cork, Ireland

$\mathrm{Tel}+353214901326$

Fax +353214901446

Email al.leblond@ucc.ie

\begin{abstract}
Despite advances in the management of myocardial infarction, congestive heart failure following myocardial infarction continues to be a major worldwide medical problem. Mononuclear cells from bone marrow are currently being studied as potential candidates for cellbased therapy to repair and regenerate damaged myocardium, with mixed results. The success of this strategy requires structural repair through both cardiomyogenesis and angiogenesis but also functional repair. However, pre-clinical and clinical studies with the intracoronary administration of cells indicate limited cardiomyogenesis and cell survival, controversial functional benefit and suggest paracrine effects mediated by the administered cells. Further investigations for optimizing therapeutic benefit focus on the requirement for stable cell engraftment and the involvement of cytokines in this process. This includes a large and varied range of strategies including cell or heart pre-treatment, tissue engineering and protein therapy. Although cellbased therapy holds promise in the future treatment of myocardial infarction, its current use is significantly hampered by biological and technological challenges.
\end{abstract}

Keywords: bone marrow mononuclear cells, myocardial infarction, cardiac cell therapy

\section{From bench to bedside}

Despite advances in the management of myocardial infarction (MI), congestive heart failure following MI continues to be a major worldwide medical problem. Current pharmacologic and interventional strategies fail to regenerate dead myocardium and are usually insufficient to address the challenge caused by necrotic cardiac myocytes. There is growing evidence suggesting that heart muscle may have the ability to partially repair itself through activation of resident cardiac stem cells ${ }^{1}$ or through recruitment of a stem cell population from other tissues, such as bone marrow (BM). ${ }^{2,3}$

Many cell types from BM are currently being studied as potential candidates for cell-based therapy to repair and regenerate damaged myocardium after MI. Successful cardiac regeneration requires the production of functional cardiomyocytes and also the development of a network of blood vessels to support and nourish these newly formed cardiomyocytes. Thus the challenge of cell-based therapy for MI is to identify one or several precursors or progenitor cells capable of giving rise to cardiomyocytes, smooth muscles cells and endothelial cells in order to restore cardiac function. In these settings unselected BM mononuclear cells (MNCs) or selected BM-MNCs or BM-derived mesenchymal stem cells (MSCs) have undergone numerous experimental, pre-clinical and clinical studies. Newly formed myocardium, occupying the majority of the infarcted part of the left ventricle (LV), were obtained after transplanting male lineage-negative c-kit-positive BM cells from male transgenic mice into female animals 3 to 5 hours 
after coronary artery ligation. ${ }^{4}$ The origin of the cells in regenerating myocardium was determined by expression of enhanced green fluorescent protein and the presence of $\mathrm{Y}$ chromosome. ${ }^{4}$ Subsequently another group injected CD34 positive hematopoietic stem cells mobilized from the BM by granulocyte colony-stimulating factor (G-CSF) intravenously into rats after ligation of the left anterior descending coronary artery. ${ }^{5}$ These cells also infiltrated the damaged myocardium within 48 hours in infarcted, but not in shamoperated animals. Microvascularity was increased and matrix deposition and fibrosis were reduced in the infarct zone and in the tissue adjoining the infarction. ${ }^{5}$ In numerous animal models of transplantation following MI, MSCs derived from BM differentiate into both cardiomyocytes and endothelial cells in vivo. ${ }^{6-9}$ Synergistic functional effects of MSCs with co-transplanted fetal cardiomyocytes in post-infarcted pig model has also been reported. ${ }^{10}$ Further human investigation in sex-mismatched heart transplant subjects revealed that recipient cardiomyocytes were present in donor hearts, indicating the migration of BM-derived stem cells into the transplanted donor heart. ${ }^{11,12}$

Evidence for vasculogenesis and arteriogenesis was found after delivery of BM-derived stem cells in transgenic mice with myocytes, endothelial and smooth muscle cells proliferating in the infarcted region and originating from the donor stem cells. ${ }^{13}$ However, some laboratories have failed to reproduce these initial results showing that transplanted cells only expressed surface markers of their own stem cell line, suggesting that any functional improvement once again may be due to indirect effects. ${ }^{14-16}$

After promising results of experimental cardiac stem cell therapy with significant improvement in LV function, this new type of regenerative treatment has been introduced relatively early in humans. Several randomized, double-blinded, placebo controlled, multicenter studies have evaluated the therapeutic potential of BM-derived stem cells in MI to improve cardiac function. ${ }^{17-20}$

Most clinical studies have focused on the intracoronary administration of the entire bone marrow MNC fraction ${ }^{21-26}$ with the rationale that any therapeutic effect depends on the balance between multiple cell types, and by using a large panel of precursors, no potentially beneficial cell type is omitted. This is supported by the results of recent doubleblind and placebo-controlled trials in patients with MI. ${ }^{23,24}$ These clinical studies indicate mixed and discrepant results (for review see) ${ }^{17}$ which could be explained by the differences in patient- and cell-related factors (eg, dosing and timing of delivery, technique of cell processing) across various studies.
Indeed, the results of several observational studies suggested a favorable effect of bone marrow cell infusion after acute MI on LV function with a reduced infarct size. However, a number of randomized controlled studies yielded mixed results in terms of therapeutic benefit. Magnetic resonance imaging (MRI) in the BOOST and the ASTAMI studies revealed that bone marrow cell transfer did not improve LV ejection fraction (LVEF) or decrease infarct size. ${ }^{26,27}$ In contrast other studies show that intracoronary bone marrow cell infusion is associated with a significant improvement in LVEF on LV angiography and a reduced infarct size. ${ }^{28}$ In the largest study to date (the REPAIR-AMI study), the mean (SD) absolute improvement in LVEF on LV angiography at 4 months was $5.5 \%$ in the bone marrow cell group, as compared to $3.0 \%$ in the placebo group $(P=0.01) .{ }^{24}$ Subgroup analysis revealed that patients with an impaired baseline LVEF $(<48.9 \%)$ and patients in whom cells were transplanted 4 days after infarction derived most benefit. Intriguingly, patients receiving bone marrow cell infusion exhibited a significantly lower rate of pre-specified major cardiovascular events. ${ }^{29}$ The latter positive effect, however, seemed to be mainly driven by a relatively high rate of cardiovascular adverse events in the placebo group. ${ }^{30}$ The lack of consistent results on the efficacy of bone marrow cell transfer for acute infarction is probably related to differences in enrolment criteria, bone marrow cell processing, the moment of cell delivery after infarction, and the imaging method used to assess changes in LV function, myocardial perfusion and infarct size. The latter issue emphasizes the need for the use of highly accurate, quantitative imaging techniques such as cine MRI, positron emission tomography (PET) and contrast enhanced MRI.

In patients with chronic MI, several studies suggested a significant improvement in LV function after bone marrow cell transplantation. ${ }^{31-36}$ The IACT investigators reported that bone marrow cell injection was associated with an $8 \%$ increase in LVEF on LV angiography. ${ }^{31}$ In this study, the increase in LVEF was associated with a reduced infarct size and an improved infarct wall motion velocity. In the TOPCARE-CHD study bone marrow cell transplantation in patients with chronic infarction was associated with a $2.9 \%$ increase in LVEF on LV angiography at 3 months. ${ }^{21}$ No improvement in LV function was observed in patients receiving circulating progenitor cells or in patients who received no cell infusion. Although the preliminary efficacy results seem to be encouraging, it should be emphasized that the current studies are limited by the small sample size, the short follow-up period, and the heterogeneity of the baseline patient characteristics. The latter issue is particularly relevant 
to the IACT study in which the baseline LVEF ranged from $38 \%$ to $69 \% .^{31}$ Another limitation of the current studies is the non-randomized trial design of most of them. Therefore, randomized, double-blind, placebo-controlled studies are needed to assess the efficacy of cell therapy in patients with chronic infarction.

From a functional cellular perspective myocardial infarction leads to a loss of approximately one billion of cardiomyocytes. ${ }^{37}$ However, so far no study has been able to demonstrate an equal repopulation with transdifferentiated cardiomyocytes after cell therapy. Experimental studies suggest that the transferred cells are largely eliminated from the heart within the first 24 to 48 hours after intracoronary infusion. ${ }^{14,38,39}$ Furthermore, a recent study using two-photon laser fluorescence microscopy has demonstrated the inability of engrafted bone marrow cells to respond to a depolarizing current by a cyclic calcium transient, which is fundamental attribute of cardiomyocytes. ${ }^{40}$

A recent genetic proof of-concept study, however, showed that transplanted bone marrow cells can induce cardiac gene expression, although the number of these cells that acquire a cardiac phenotype is low. ${ }^{41}$ The concept of cell fusion, when transplanted cells fuse with other cells, resulting in a hybrid cell progenitor with differentiated cell markers, has been demonstrated in vitro, but its clinical relevance is disputed and generally considered to be small in regard to cardiac regeneration. ${ }^{16}$

Nonetheless, for the present, we are faced with a paradox: the overwhelming conclusion from multiple sources is that cell transplant translates into a range of beneficial responses, but these occur in an environment characterized by a lack of clinically or pathophysiologically relevant cell transdifferentiation, retention, and survival. Although a vigorous regenerative capacity has not been demonstrated with current cell populations, that does not preclude the potential for enhancement of endogenous repair capabilities through a variety of other mechanisms, nor does it mean that ongoing efforts to enhance regeneration are doomed to failure. ${ }^{42}$

Several studies have proposed that the functional benefits observed after BM-MNC transfer in animal models of cardiac injury might be related to secretion of soluble factors that, acting in an autocrine fashion on the administered stem cells or in a paracrine fashion on nearby host cells, protect the heart, attenuate pathological ventricular remodeling, induce neovascularization and promote repair. ${ }^{43-45}$ This point was first demonstrated in a series of experiments utilizing Akt-expressing MSCs. ${ }^{43,46,47}$ In the initial study, transplantation of the stem cells resulted in a marked reduction in infarct size and a concomitant improvement in cardiac function as compared to untreated hearts. Akt1-expressing MSC secrete sFRP2 that protects cardiomyocytes from hypoxia-induced apopotosis. ${ }^{48,49}$ Despite enhanced cardiac function, the differentiation of MSC to cardiomyocytes is limited d7,50-52 $^{47}$ suggesting that alternative mechanisms contributed to treatment effect. In support of this, injection of conditioned medium from cultured stem cells completely recapitulated the effect observed with stem cell transplantation, ${ }^{43,44,53}$ indicating that a paracrine activity underlies at least in part the cardioprotection observed with this cell treatment. ${ }^{54}$ Indeed, it has been shown that BM-MNCs produce and secrete a broad of variety of cytokines, chemokines and growth factors that may potentially be involved in cardiac repair such as bFGF (basic fibroblast growth factor), ${ }^{55}$ PDGF (platelet derived growth factor), VEGF (vascular endothelial growth factor), HGF (hepatocyte growth factor) and IGF-1 (insulin growth factor) (Table1). Furthermore, hypoxic stress increases the production of several of these factors: ${ }^{45}$ MSCs exposed to hypoxic conditions express VEGF, which may enhance their survival. ${ }^{44,56,57}$ In addition, the up-regulation of VEGF in the donor cells also promotes angiogenesis and improves regional blood flow in the surrounding ischemic host myocardium. ${ }^{56,58}$ Transplantation of MSC resulted in increase expression of bFGF and VEGF, which was associated with improvements in both perfusion and function. ${ }^{45}$ Hepatocyte growth factor (HGF) is another secreted angiogenic and cardioprotective factor which has been observed to enhance neovascularization and reduce apoptosis ${ }^{59}$ and IGF1 is known to mediate antiapoptotic effects. ${ }^{60}$ According to these findings, the beneficial effects of BM-MNCs transplantation are probably mediated primarily through the preservation, not regeneration, of cardiac myocytes within the infarcted area. ${ }^{61}$ These paracrine factors may influence adjacent cells and exert their actions via several mechanisms including myocardial protection, neovascularization and perhaps activation of resident cardiac stem cells and/or stimulation of endogenous cardiomyocyte replication (for review see) ${ }^{62}$ (Table 1). Thus this hypothesis of paracrine effects extends the traditional concept of stem cell niche to include the influence of stem cell-associated factors on the microenvironment modulating both stem cell biology and the tissue response.

\section{From bedside to bench}

It is reasonable to argue based on clinical trials to date that intracoronary infusion of BM-MNCs is safe and feasible and that the transplanted cells are likely to stimulate the endogenous regenerative myocardial processes, perhaps through 
Table I Paracrine factors secreted by bone marrow-derived stem cells and their paracrine effects

\begin{tabular}{|c|c|c|c|c|c|}
\hline \multirow[t]{2}{*}{ Cells } & \multirow[t]{2}{*}{ Paracrine factors } & \multicolumn{4}{|c|}{ Investigated paracrine effects } \\
\hline & & Myocardial protection & Neovascularization & Cardiac regeneration & References \\
\hline \multirow[t]{2}{*}{ BM-MNCs } & VEGF & X (antiapoptotic effect) & $x$ & & 36 \\
\hline & VEGF, PDGF, IGF-I & $x$ & & & 33 \\
\hline \multirow[t]{2}{*}{ BMCs } & VEGF, bFGF, SDFI I, IGF-I & X (antiapoptotic effect) & & & 37 \\
\hline & VEGF, bFGF, HGF, IGF-I & $X$ (antiapoptotic effect) & $x$ & $\begin{array}{l}\text { X (cardiomyocyte } \\
\text { proliferation) }\end{array}$ & 38 \\
\hline \multirow[t]{2}{*}{ MSCs } & bFGF, VEGF, SDF-I & X (antiapoptotic effect) & $x$ & & 39 \\
\hline & VEGF, bFGF, HGF, IGF-I & $X$ (antifibrotic effect) & $x$ & $x$ & 29,40 \\
\hline \multirow[t]{2}{*}{ MSCs-CM } & VEGF, bFGF, IGF-I, SDF-I & $X$ (antifibrotic effect) & $x$ & $x$ & $28-30,4 I-42$ \\
\hline & VEGF, HGF & $X$ (antifibrotic effect) & $\mathrm{x}$ & & 43 \\
\hline MSCs-CM & Sfrp2 & $X$ (antiapoptotic effect) & & & 35 \\
\hline
\end{tabular}

Abbreviations: BM-MNCs, bone marrow mononuclear cells; BMCs, total bone marrow cells; MSCs, mesenchymal stem cells; CM, conditioned media; bFGF, basic fibroblast growth factor; HGF, hepatocyte growth factor; IGF-I, insulin growth factor I; PDGF, platelet-derived growth factor; VEGF, vascular endothelial growth factor; SDF-I, stromalderived factor $\mathrm{I}$.

a combination of direct and indirect effects. However given that precise mechanisms of benefit are yet to be clearly elucidated. Future research in the field will need to focus on the requirement for stable engraftment for long-term therapeutic efficacy, and on the involvement of cytokines in this process. Indeed, based on the recent basic observations, activation of signaling cascades by secreted cytokines, ultimately giving rise to enhanced survival and/or contractility of host cardiomyocytes could constitute a useful direction for targeted preclinical investigation. A major limitation of current cell therapy is the low "payload" of therapeutic cells delivered to the site of injury.

Despite positive results in early and later clinical trials, in vivo tracking of the intracoronary injected cells in several studies revealed that, within hours of their delivery, around $90 \%$ of the cells disappeared and $<1 \%$ of donor cells were identified 4 weeks after transplantation. ${ }^{38,63}$ This very low rate of sustained cell engraftment is presumably due to cell stress, the hostile environment around the infarcted tissue (inflammation, hypoxia), insufficient vascular supply and elaboration of inflammatory cytokines resulting from ischemia and/or cell death. ${ }^{64-66}$ Increased cell dosing therefore appears one of the significant challenges facing BM cell therapy. ${ }^{67,68}$ A major lesson from preclinical and early clinical trials is that enhancement of cell engraftment is mandatory for optimizing the therapeutic benefits of the procedure. This scalability issue is particularly relevant to heart failure, where the cardiomyocyte deficit has been estimated to be in the range of one billion cells. ${ }^{37}$

The strategy of cell therapy is to repair injured tissue through delivery of an adequate cell dose to an area of interest.
Achieving this goal requires a conducive microenvironment for cell survival, retention, and/or homing, among other factors. Currently available routes of administration include intravenous, ${ }^{69}$ intracoronary, ${ }^{70}$ transmyocardial (by direct epicardial injection) ${ }^{71}$ catheter-based transendocardial injection using electromechanical voltage mapping, ${ }^{72}$ and a recently implemented approach of transvenous injection into coronary veins ${ }^{73}$ (for review of their respective advantages and disadvantages). ${ }^{74}$ At present, no single strategy has emerged as the preferred technique. ${ }^{75}$ The percentage of transplanted cells retained in the myocardium appears to be strongly dependent on the local milieu. In particular, the strength of homing signals may vary in different clinical scenarios. In general, the intracoronary infusion technique seems to be most suited for the treatment of recently infarcted myocardium when high levels of homing signals are expressed. ${ }^{76}$ The rate of homing has recently been shown to be time-dependent, being greater when cells are delivered shortly after the acute ischemic event. ${ }^{77}$

Further strategies to augment cell engraftment include pre-treating the cells to stimulate incorporation: most of the studies have used vector systems to increase the expression of anti-apoptotic, "cytoprotective" genes (Akt, Bcl2 GSK, $\mathrm{IlK}$, telomerase, eNOS) promoting survival of injected or infused cells (for review see). ${ }^{78}$

Pre-treating the target tissue in order to provide additional cytokines and stimulate stem cell incorporation would be another strategy. Indeed in patients with MI, the expression of VEGF and stromal-derived factor 1 (SDF-1) was significantly suppressed compared to controls suggesting a lack of recruitment signals in these patients. ${ }^{79}$ Therefore injection of 
cytokines may be useful to attract stem cells in the absence of necrosis or acute ischemia. Indeed, local injection of SDF-1 in ischemic hind limbs increased the recruitment of intravenously infused myeloid-derived endothelial progenitor cells (EPC) ${ }^{80}$ SDF-1 stimulates the CXCR4 receptor, which is expressed on EPC and BMC, and, thereby, acts as a chemotactic and pro-migratory factor. ${ }^{81}$ Moreover, an activation of ischemic tissue by low energy shock wave application stimulated the expression of SDF-1 and VEGF within the target zone and promoted homing of intravenously infused EPC. ${ }^{82}$ Changing the environment may also be an attractive approach for increasing the efficiency of intramuscular injected cells. This point was recently illustrated with the local myocardial delivery of both insulin-like growth factor 1 (IGF-1) using biotinylated peptide nanofibers and cells (neonatal rat cardiomyocytes or endogenous cardiac progenitor cells). ${ }^{83,84}$ This combined strategy led to an improvement of cardiac recovery and function after $\mathrm{MI}$ in rats.

Pre-treating the heart with ultrasound and microbubbles may also enhance cell delivery and induce cardiac beneficial effects. Indeed ultrasound contrast agents in current clinical use are small ( 1 to $4 \mu \mathrm{m}$ ) gas-filled "microbubbles" comprised a perfluorocarbon gas that is encapsulated by a biocompatible shell. ${ }^{85}$ These agents freely transit through the microcirculation; high-powered ultrasound can be used to selectively destroy these microbubbles, with consequent release of their contents into the organ of interest. This strategy has been exploited for the targeted delivery of genes that are incorporated into the microbubble shell prior to systemic injection. Early studies demonstrated capacity to safely deliver and direct reporter gene expression in the heart. ${ }^{86-88}$ Recently, this approach was applied to address a challenge encountered in cell-based therapies for the heart; improving the microenvironment supporting exogenously delivered cells will improve cell engraftment. ${ }^{89,90}$ The authors demonstrated that the ultrasound-targeted microbubble destruction successfully delivered VEGF and stem cell factor (SCF) genes into the infarcted heart, increased vascular density and improved myocardial perfusion and ventricular function. However, it is still not clear whether "progenitor cells" were mobilized, as the flow cytometry data presented were somewhat equivocal as to the presence of discrete subpopulations of c-kit positive cells. ${ }^{89}$ In a second study, the authors demonstrated that targeted pretreatment with ultrasound-targeted microbubble destruction improves regional adhesion and transendothelial migration of intravascularly transplanted MSC in non-ischemic and post-ischemic myocardium. ${ }^{90}$ Indeed acute release of proinflammatory cytokines, induction of MMP activity and reduction of total laminin content were limited to myocardial segments pre-treated by targeted ultrasound-mediated stimulation of microbubbles. Thus, the site-directed augmentation of myocardial MSC engraftment is associated with ultrasound-targeted microbubble destruction related effects ${ }^{90}$ Future studies might include an accurate characterization of the recruited progenitors cells and should also determine the benefits of combined gene therapy and cell therapy after pretreatment with ultrasound and microbubbles.

Tissue engineering could be another strategy to deliver stem cells and enhance engraftment. This strategy has been proposed for heart valves ${ }^{91}$ and myocardial muscle. ${ }^{92}$ This is an emerging field that could give hope to patients needing heart transplants or smaller structures such as heart patches in the case of congenital heart disease. Cardiac tissue engineering involves the synthesis of a preformed three-dimensional scaffold or patch combined with living cells. The main function of the biomaterial is to act as a vehicle for the delivery of cells to the infarcted myocardium (for review see). ${ }^{93}$

Polymers, both natural and synthetic, are the largest class of engineered biomaterials used today as scaffolds for myocardial tissue engineering. Natural and synthetic biomaterials have been used separately or in combination to repair in vivo the myocardium (for review see). ${ }^{93}$ Different types of cells including BM-MNCs and MSCs but also foetal or neonatal rodent cardiac cells were seeded onto these scaffolds. ${ }^{93}$

Synthetic polymers can also be deployed in part using the cell-sheeting methods which involve culture of cells on temperature-responsive dishes. ${ }^{94}$ These dishes are made of a specific polymers that are hydrophobic and cell-adhesive at $37^{\circ} \mathrm{C}$. However by reducing the temperature as little as $5^{\circ} \mathrm{C}$, the polymer is caused to rapidly hydrate and swell, becoming hydrophilic and non-adhesive to cells. This method facilitates the production of individual cell sheets, forming a 3D simultaneously beating myocardial tissue. ${ }^{95-97}$ Spontaneous pulsation was observed in vivo, in nude rats, 3 days post-implantation and this was preserved for up to 1 year, with graft integration increasing proportionally with host growth. ${ }^{98}$ More recently, a group has reported the success of implanting a $100 \mathrm{~mm}$ thick cardiac tissue, made from 6 monolayered MSC sheets layered together and implanted onto the infarcted region, improving the infarcted wall thickness. ${ }^{99}$ Finally a synthetic polymer seeded with BM-MNCs was recently suggested as a cardiac patch for rat hearts post-MI, ${ }^{100}$ reporting reduced LV remodeling, and preserved systolic function of the LV.

Natural materials, including an artificial extracellular matrix composed of collagen type I and glycosaminoglycan 
(both abundant proteins in the extracellular matrix of the body) were also used to transplant MSCs onto the infarcted rat myocardium, resulting in neovascularization in this specific area. ${ }^{101}$ However, as the mechanical properties of collagen are poor, researchers have attempted to combine synthetic polymers with collagen to engineer a tailormade scaffold matching the properties of the heart. An example of this was reported in a study in which MSCs were transplanted into infarcted rat hearts with promising results. ${ }^{62,102}$

Although cardiac tissue engineering has been shown to have successful outcomes in experimental studies, it is still in its formative years and further investigations are required before clinical application.

The demonstration that stem cells may secrete therapeutic factors also provides a potential therapeutic alternative to cell therapy in that, rather than administering cells, one may be able to administer specific proteins produced by these cells. If specific paracrine cell-derived factors that improve cardiac function are identified, then protein-based therapy might be easily translated into clinical benefits. ${ }^{103}$ A known quantity of protein can be administered using intravenous, intracoronary, or intramyocardial approaches. The limitation of protein therapy is the necessity to maintain therapeutic concentration to induce the desired effect for the necessary length of time. Establishing the threshold concentration and the necessary treatment time remains to be determined and represents a challenging task. Different actions may require different concentrations and timing. Substantial differences between animal models and humans further complicate this translational scenario. For example, it has been shown that a single dose of specific growth factors is effective in enhancing neovascularization in animals but not in humans. ${ }^{104,105}$ To overcome the problems of protein stability and pharmacokinetics, a variety of strategies have emerged for manipulating protein properties including stability, specificity, immunogenicity, and pharmacokinetics. ${ }^{106}$ Techniques for altering these properties include manipulation of primary structure, incorporation of chemical and post-translation modifications, and utilization of fusion partners. Various delivery strategies have also evolved over the past few years to improve delivery of proteins and peptides, including the use of biopolymers and nanomaterials for controlled release of proteins ${ }^{61,107}$ and delivery via non-invasive routes such as subcutaneous release or dermal patches. Together these bioengineering approaches may be synergized with cell therapy to the benefit of both.

\section{Conclusion}

The recent demonstration of paracrine mechanisms improves our understanding of stem cell biology and stem cell action in tissue repair and regeneration. Although stem cell therapy holds promise in the future treatment of heart disease such as MI, its current use is significantly hampered by biological and technological challenges.

\section{Disclosures}

The authors declare no conflicts of interest.

\section{References}

1. Bearzi C, Rota M. Human cardiac stem cells. Proc Natl Acad Sci USA. 2007;104(35):14068-14073.

2. Wagers AJ, Weissman IL. Plasticity of adult stem cells. Cell. 2004; 116(5):639-648.

3. Anversa P, Leri A. Cardiac regeneration. J Am Coll Cardiol. 2006;47(9):1769-1776.

4. Orlic D, Kajstura J. Mobilized bone marrow cells repair the infarcted heart, improving function and survival. Proc Natl Acad Sci U S A. 2001;98(18):10344-10349.

5. Kocher AA, Schuster MD. Neovascularization of ischemic myocardium by human bone-marrow-derived angioblasts prevents cardiomyocyte apoptosis, reduces remodeling and improves cardiac function. Nat Med. 2001;7(4):430-436.

6. Antonitsis P, Ioannidou-Papagiannaki E. Cardiomyogenic potential of human adult bone marrow mesenchymal stem cells in vitro. Thorac Cardiovasc Surg. 2008;56(2):77-82.

7. Nomura T, Ashihara E. Therapeutic potential of stem/progenitor cells in human skeletal muscle for cardiovascular regeneration. Curr Stem Cell Res Ther. 2007;2(4):293-300.

8. Tousoulis D, Briasoulis A. Heart regeneration: what cells to use and how? Curr Opin Pharmacol. 2008;8(2):211-218.

9. Wold LE, Dai W. Stem cell therapy in the heart and vasculature. Methods Mol Med. 2007;139:355-365.

10. Min JY, Sullivan MF. Significant improvement of heart function by cotransplantation of human mesenchymal stem cells and fetal cardiomyocytes in postinfarcted pigs. Ann Thorac Surg. 2002;74(5): $1568-1575$.

11. Quaini F, Urbanek K. Chimerism of the transplanted heart. $N$ Engl $J$ Med. 2002;346(1):5-15.

12. Muller P, Pfeiffer P. Cardiomyocytes of noncardiac origin in myocardial biopsies of human transplanted hearts. Circulation. 2002;106(1): 31-35.

13. Orlic D, Kajstura J. Bone marrow cells regenerate infarcted myocardium. Nature. 2001;410(6829):701-705.

14. Murry CE, Soonpaa MH. Haematopoietic stem cells do not transdifferentiate into cardiac myocytes in myocardial infarcts. Nature. 2004;428(6983):664-668.

15. Balsam LB, Wagers AJ. Haematopoietic stem cells adopt mature haematopoietic fates in ischaemic myocardium. Nature. 2004;428(6983): 668-673.

16. Nygren JM, Jovinge S. Bone marrow-derived hematopoietic cells generate cardiomyocytes at a low frequency through cell fusion, but not transdifferentiation. Nat Med. 2004;10(5):494-501.

17. Menasche P. Cell-based therapy for heart disease: a clinically oriented perspective. Mol Ther. 2009;17(5):758-766.

18. Lipinski MJ, Biondi-Zoccai GG. Impact of intracoronary cell therapy on left ventricular function in the setting of acute myocardial infarction: a collaborative systematic review and metaanalysis of controlled clinical trials. J Am Coll Cardiol. 2007;50(18): $1761-1767$. 
19. Murry CE, Field LJ. Cell-based cardiac repair: reflections at the 10-year point. Circulation. 2005;112(20):3174-3183.

20. Rubart M, Field LJ. Stem cell differentiation: cardiac repair. Cells Tissues Organs. 2008;188(1-2):202-211.

21. Assmus B, Schachinger V. Transplantation of Progenitor Cells and Regeneration Enhancement in Acute Myocardial Infarction (TOPCARE-AMI). Circulation. 2002;106(24):3009-3017.

22. Strauer BE, Brehm M. Repair of infarcted myocardium by autologous intracoronary mononuclear bone marrow cell transplantation in humans Circulation. 2002;106(15):1913-1918.

23. Wollert KC, Meyer GP. Intracoronary autologous bone-marrow cell transfer after myocardial infarction: the BOOST randomised controlled clinical trial. Lancet. 2004;364(9429):141-148.

24. Schachinger V, Erbs S. Intracoronary bone marrow-derived progenitor cells in acute myocardial infarction. $N$ Engl J Med. 2006;355(12) 1210-1221.

25. Janssens S, Dubois C. Autologous bone marrow-derived stem-cell transfer in patients with ST-segment elevation myocardial infarction double-blind, randomised controlled trial. Lancet. 2006;367(9505) 113-121.

26. Lunde K, Solheim S. Intracoronary injection of mononuclear bone marrow cells in acute myocardial infarction. $N$ Engl J Med. 2006; 355(12):1199-1209.

27. Meyer GP, Wollert KC. Intracoronary bone marrow cell transfer after myocardial infarction: eighteen months' follow-up data from the randomized, controlled BOOST (BOne marrOw transfer to enhance ST-elevation infarct regeneration) trial. Circulation. 2006;113(10): 1287-1294.

28. Chen SL, Fang WW. Effect on left ventricular function of intracoronary transplantation of autologous bone marrow mesenchymal stem cell in patients with acute myocardial infarction. Am J Cardiol. 2004;94(1): 92-95.

29. Schachinger V, Erbs S. Improved clinical outcome after intracoronary administration of bone-marrow-derived progenitor cells in acute myocardial infarction: final 1-year results of the REPAIR-AMI trial. Eur Heart J. 2006;27(23):2775-2783.

30. Arnesen H, Lunde K. Cell therapy in myocardial infarction. Lancet. 2007;369(9580):2142-2143.

31. Strauer BE, Brehm M. Regeneration of human infarcted heart muscle by intracoronary autologous bone marrow cell transplantation in chronic coronary artery disease: the IACT Study. $J$ Am Coll Cardiol. 2005;46(9):1651-1658.

32. Katritsis DG, Sotiropoulou PA. Transcoronary transplantation of autologous mesenchymal stem cells and endothelial progenitors into infarcted human myocardium. Catheter Cardiovasc Interv. 2005;65(3):321-329.

33. Erbs S, Linke A. Transplantation of blood-derived progenitor cells after recanalization of chronic coronary artery occlusion: first randomized and placebo-controlled study. Circ Res. 2005;97(8) 756-762.

34. Assmus B, Fischer-Rasokat U. Transcoronary transplantation of functionally competent BMCs is associated with a decrease in natriuretic peptide serum levels and improved survival of patients with chronic postinfarction heart failure: results of the TOPCARE-CHD Registry. Circ Res. 2007;100(8):1234-1241.

35. Beeres SL, Bax JJ. Intramyocardial injection of autologous bone marrow mononuclear cells in patients with chronic myocardial infarction and severe left ventricular dysfunction. Am J Cardiol. 2007;100(7): 1094-1098.

36. Yao K, Huang R. Administration of intracoronary bone marrow mononuclear cells on chronic myocardial infarction improves diastolic function. Heart. 2008;94(9):1147-1153.

37. Murry CE, Reinecke H. Regeneration gaps: observations on stem cells and cardiac repair. J Am Coll Cardiol. 2006;47(9):1777-1785.

38. Doyle B, Kemp BJ. Dynamic tracking during intracoronary injection of 18F-FDG-labeled progenitor cell therapy for acute myocardial infarction. J Nucl Med. 2007;48(10):1708-1714.
39. Tossios P, Krausgrill B. Role of balloon occlusion for mononuclear bone marrow cell deposition after intracoronary injection in pigs with reperfused myocardial infarction. Eur Heart J. 2008;29(15):1911-1921.

40. Scherschel JA, Soonpaa MH. Adult bone marrow-derived cells do not acquire functional attributes of cardiomyocytes when transplanted into peri-infarct myocardium. Mol Ther. 2008;16(6):1129-1137.

41. Rupp S, Koyanagi M. Genetic proof-of-concept for cardiac gene expression in human circulating blood-derived progenitor cells. $J \mathrm{Am}$ Coll Cardiol. 2008;51(23):2289-2290.

42. Sussman MA, Murry CE. Bones of contention: marrow-derived cells in myocardial regeneration. $J$ Mol Cell Cardiol. 2008;44(6): 950-953.

43. Gnecchi M, He H. Paracrine action accounts for marked protection of ischemic heart by Akt-modified mesenchymal stem cells. Nat Med. 2005;11(4):367-368.

44. Gnecchi M, He H. Evidence supporting paracrine hypothesis for Akt-modified mesenchymal stem cell-mediated cardiac protection and functional improvement. Faseb J. 2006;20(6):661-669.

45. Kinnaird T, Stabile E. Local delivery of marrow-derived stromal cells augments collateral perfusion through paracrine mechanisms. Circulation. 2004;109(12):1543-1549.

46. Mangi AA, Noiseux N. Mesenchymal stem cells modified with Akt prevent remodeling and restore performance of infarcted hearts. Nat Med. 2003;9(9):1195-1201.

47. Noiseux N, Gnecchi M. Mesenchymal stem cells overexpressing Akt dramatically repair infarcted myocardium and improve cardiac function despite infrequent cellular fusion or differentiation. Mol Ther. 2006;14(6):840-850.

48. Mirotsou M, Zhang Z. Secreted frizzled related protein 2 (Sfrp2) is the key Akt-mesenchymal stem cell-released paracrine factor mediating myocardial survival and repair. Proc Natl Acad Sci U S A. 2007;104(5):1643-1648.

49. Zhang Z, Deb A. Secreted frizzled related protein 2 protects cells from apoptosis by blocking the effect of canonical Wnt3a. J Mol Cell Cardiol. 2009;46(3):370-377.

50. Fazel S, Chen L. Cell transplantation preserves cardiac function after infarction by infarct stabilization: augmentation by stem cell factor. J Thorac Cardiovasc Surg. 2005;130(5):1310.

51. Silva GV, Litovsky S. Mesenchymal stem cells differentiate into an endothelial phenotype, enhance vascular density, and improve heart function in a canine chronic ischemia model. Circulation. 2005;111(2):150-156.

52. Rose RA, Jiang H. Bone marrow-derived mesenchymal stromal cells express cardiac-specific markers, retain the stromal phenotype, and do not become functional cardiomyocytes in vitro. Stem Cells. 2008;26(11):2884-2892.

53. Takahashi M, Li TS. Cytokines produced by bone marrow cells can contribute to functional improvement of the infarcted heart by protecting cardiomyocytes from ischemic injury. Am J Physiol Heart Circ Physiol. 2006;291(2):H886-H893.

54. Doyle B, Sorajja P. Progenitor cell therapy in a porcine acute myocardial infarction model induces cardiac hypertrophy, mediated by paracrine secretion of cardiotrophic factors including TGFbeta1. Stem Cells Dev. 2008;17(5):941-951.

55. Kano MR, Morishita Y. VEGF-A and FGF-2 synergistically promote neoangiogenesis through enhancement of endogenous PDGF-B-PDGFRbeta signaling. J Cell Sci. 2005;118(Pt 16):3759-3768.

56. $\mathrm{Xu} \mathrm{M}$, Uemura $\mathrm{R}$. In vitro and in vivo effects of bone marrow stem cells on cardiac structure and function. J Mol Cell Cardiol. 2007;42(2): 441-448.

57. Li W, Ma N. Bcl-2 engineered MSCs inhibited apoptosis and improved heart function. Stem Cells. 2007;25(8):2118-2127.

58. Tang YL, Zhao Q. Autologous mesenchymal stem cell transplantation induce VEGF and neovascularization in ischemic myocardium. Regul Pept. 2004;117(1):3-10.

59. Rehman J, Traktuev D. Secretion of angiogenic and antiapoptotic factors by human adipose stromal cells. Circulation. 2004;109(10):1292-1298. 
60. Sadat $\mathrm{S}$, Gehmert $\mathrm{S}$. The cardioprotective effect of mesenchymal stem cells is mediated by IGF-I and VEGF. Biochem Biophys Res Commun. 2007;363(3):674-679.

61. Zhang G, Nakamura Y. Controlled release of stromal cell-derived factor-1 alpha in situ increases c-kit+ cell homing to the infarcted heart. Tissue Eng. 2007;13(8):2063-2071.

62. Gnecchi M, Zhang Z. Paracrine mechanisms in adult stem cell signaling and therapy. Circ Res. 2008;103(11):1204-1219.

63. Zeng $\mathrm{L}, \mathrm{Hu} \mathrm{Q}$. Bioenergetic and functional consequences of bone marrow-derived multipotent progenitor cell transplantation in hearts with postinfarction left ventricular remodeling. Circulation. 2007;115(14):1866-1875.

64. Haider H, Ashraf M. Strategies to promote donor cell survival: combining preconditioning approach with stem cell transplantation. J Mol Cell Cardiol. 2008;45(4):554-566.

65. Robey TE, Saiget MK. Systems approaches to preventing transplanted cell death in cardiac repair. J Mol Cell Cardiol. 2008;45(4):567-581.

66. Hofmann M, Wollert KC. Monitoring of bone marrow cell homing into the infarcted human myocardium. Circulation. 2005;111(17): 2198-2202.

67. Martin-Rendon E, Brunskill SJ. Autologous bone marrow stem cells to treat acute myocardial infarction: a systematic review. Eur Heart J. 2008;29(15):1807-1818.

68. Forrester JS, White AJ. New paradigms of myocardial regeneration post-infarction: tissue preservation, cell environment, and pluripotent cell sources. JACC Cardiovasc Interv. 2009;2(1):1-8.

69. Barbash IM, Chouraqui P. Systemic delivery of bone marrow-derived mesenchymal stem cells to the infarcted myocardium: feasibility, cell migration, and body distribution. Circulation. 2003;108(7): 863-868.

70. Hamano K, Nishida M. Local implantation of autologous bone marrow cells for therapeutic angiogenesis in patients with ischemic heart disease: clinical trial and preliminary results. Jpn Circ J. 2001;65(9): 845-847.

71. Fukada J, Kurimoto Y. Long-term survival of rat cardiac allografts by intrathymic plus portal venous injections of donor bone marrow cells and short-term tacrolimus immunosuppression. Transpl Int. 2001;14(5):311-319.

72. Gyongyosi M, Lang I. Combined delivery approach of bone marrow mononuclear stem cells early and late after myocardial infarction: the MYSTAR prospective, randomized study. Nat Clin Pract Cardiovasc Med. 2009;6(1):70-81.

73. Raake P, von Degenfeld G. Myocardial gene transfer by selective pressure-regulated retroinfusion of coronary veins: comparison with surgical and percutaneous intramyocardial gene delivery. $J$ Am Coll Cardiol. 2004;44(5):1124-1129.

74. Beeres SL, Atsma DE. Cell therapy for ischaemic heart disease. Heart. 2008;94(9):1214-1226.

75. Freyman T, Polin G. A quantitative, randomized study evaluating three methods of mesenchymal stem cell delivery following myocardial infarction. Eur Heart J. 2006;27(9):1114-1122.

76. Askari AT, Unzek S. Effect of stromal-cell-derived factor 1 on stem-cell homing and tissue regeneration in ischaemic cardiomyopathy. Lancet. 2003;362(9385):697-703

77. Schachinger V, Aicher A. Pilot trial on determinants of progenitor cell recruitment to the infarcted human myocardium. Circulation. 2008;118(14):1425-1432.

78. Seeger FH, Zeiher AM. Cell-enhancement strategies for the treatment of ischemic heart disease. Nat Clin Pract Cardiovasc Med. 2007;4 Suppl 1: S110-S113.

79. van Weel V, Seghers L. Expression of vascular endothelial growth factor, stromal cell-derived factor-1, and CXCR4 in human limb muscle with acute and chronic ischemia. Arterioscler Thromb Vasc Biol. 2007;27(6):1426-1432.

80. Yamaguchi J, Kusano KF. Stromal cell-derived factor-1 effects on ex vivo expanded endothelial progenitor cell recruitment for ischemic neovascularization. Circulation. 2003;107(9):1322-1328.
81. Ceradini DJ, Kulkarni AR. Progenitor cell trafficking is regulated by hypoxic gradients through HIF-1 induction of SDF-1. Nat Med. 2004;10(8):858-864.

82. Aicher A, Heeschen C. Low-energy shock wave for enhancing recruitment of endothelial progenitor cells: a new modality to increase efficacy of cell therapy in chronic hind limb ischemia. Circulation. 2006;114(25):2823-2830.

83. Davis ME, Hsieh PC. Local myocardial insulin-like growth factor 1 (IGF-1) delivery with biotinylated peptide nanofibers improves cell therapy for myocardial infarction. Proc Natl Acad Sci U S A. 2006;103(21):8155-8160.

84. Padin-Iruegas ME, Misao Y. Cardiac progenitor cells and biotinylated insulin-like growth factor-1 nanofibers improve endogenous and exogenous myocardial regeneration after infarction. Circulation. 2009;120(10):876-887.

85. Kaul S. Myocardial contrast echocardiography: a 25-year retrospective. Circulation. 2008;118(3):291-308.

86. Shohet RV, Chen S. Echocardiographic destruction of albumin microbubbles directs gene delivery to the myocardium. Circulation. 2000. 101(22):2554-2556.

87. Bekeredjian R, Chen S. Ultrasound-targeted microbubble destruction can repeatedly direct highly specific plasmid expression to the heart. Circulation. 2003;108(8):1022-1026.

88. Korpanty G, Chen S. Targeting of VEGF-mediated angiogenesis to rat myocardium using ultrasonic destruction of microbubbles. Gene Ther. 2005;12(17):1305-1312.

89. Fujii H, Sun Z. Ultrasound-targeted gene delivery induces angiogenesis after a myocardial infarction in mice. JACC Cardiovasc Imaging. 2009;2(7):869-879.

90. Ghanem A, Steingen C. Focused ultrasound-induced stimulation of microbubbles augments site-targeted engraftment of mesenchymal stem cells after acute myocardial infarction. $J$ Mol Cell Cardiol. 2009:47(3):411-418.

91. Breuer CK, Shin'oka T. Tissue engineering lamb heart valve leaflets. Biotechnol Bioeng. 1996;50(5):562-567.

92. Zimmermann WH, Fink C. Three-dimensional engineered heart tissue from neonatal rat cardiac myocytes. Biotechnol Bioeng. 2000;68(1):106-114.

93. Jawad H, Lyon AR. Myocardial tissue engineering. Br Med Bull. 2008;87:31-47.

94. Masuda S, Shimizu T. Cell sheet engineering for heart tissue repair. Adv Drug Deliv Rev. 2008;60(2):277-285.

95. Sekiya S, Shimizu T. Bioengineered cardiac cell sheet grafts have intrinsic angiogenic potential. Biochem Biophys Res Commun. 2006;341(2):573-582.

96. Sekine H, Shimizu T. Cardiomyocyte bridging between hearts and bioengineered myocardial tissues with mesenchymal transition of mesothelial cells. J Heart Lung Transplant. 2006;25(3):324-332.

97. Shimizu T, Sekine H. Polysurgery of cell sheet grafts overcomes diffusion limits to produce thick, vascularized myocardial tissues. Faseb J. 2006;20(6):708-710.

98. Shimizu T, Yamato M. Cell sheet engineering for myocardial tissue reconstruction. Biomaterials. 2003;24(13):2309-2316.

99. Miyahara Y, Nagaya N. Monolayered mesenchymal stem cells repair scarred myocardium after myocardial infarction. Nat Med. 2006;12(4):459-465.

100. Piao H, Kwon JS. Effects of cardiac patches engineered with bone marrow-derived mononuclear cells and PGCL scaffolds in a rat myocardial infarction model. Biomaterials. 2007;28(4):641-649.

101. Xiang Z, Liao R. Collagen-GAG scaffolds grafted onto myocardial infarcts in a rat model: a delivery vehicle for mesenchymal stem cells. Tissue Eng. 2006;12(9):2467-2478.

102. Krupnick AS, Kreisel D. A novel small animal model of left ventricular tissue engineering. $J$ Heart Lung Transplant. 2002;21(2): 233-243.

103. Caplice NM. The future of cell therapy for acute myocardial infarction. Nat Clin Pract Cardiovasc Med. 2006;3 Suppl 1:S129-S132. 
104. Hughes GC, Post MJ. Translational physiology: porcine models of human coronary artery disease: implications for preclinical trials of therapeutic angiogenesis. J Appl Physiol. 2003;94(5):1689-1701.

105. Post MJ, Laham R. Therapeutic angiogenesis in cardiology using protein formulations. Cardiovasc Res. 2001;49(3):522-531.
106. Malik DK, Baboota S. Recent advances in protein and peptide drug delivery systems. Curr Drug Deliv. 2007;4(2):141-151.

107. Segers VF, Tokunou T. Local delivery of protease-resistant stromal cell derived factor-1 for stem cell recruitment after myocardial infarction. Circulation. 2007;116(15):1683-1692.

\section{Publish your work in this journal}

Stem Cells and Cloning: Advances and Applications is an international, peer-reviewed, open access journal. Areas of interest in stem cell research include: Embryonic cell stems; Adult stem cells; Blastocysts; Cordblood stem cells; Stem cell transformation and culture; Therapeutic cloning; Umbilical cord blood and bone marrow cells; Laboratory, animal and human therapeutic studies; Philosophical and ethical issues related to stem cell research. This journal is indexed on CAS. The manuscript management system is completely online and includes a quick and fair peer-review system. Visit http://www.dovepress.com/ testimonials.php to read real quotes from published authors.

\footnotetext{
Submit your manuscript here: http://www.dovepress.com/stem-cells-and-cloning-advances-and-applications-journal
} 